\title{
Kimya Öğretmenlerinin Pedagojik Muhakemelerinin Öğretim Döngüsü Boyunca Değerlendirilmesi
}

\author{
DOI: $10.26466 /$ opus.653280
}

\author{
$*$ \\ Hatice Belge Can $^{*}$ \\ * Dr. Öğr. Üyesi, Burdur Mehmet Akif Ersoy Üniversitesi, Eğitim Fakültesi, Burdur/Türkiye \\ E-Posta: hbelgecan@mehmetakif.edu.tr \\ ORCID: 0000-0003-2329-3419
}

\begin{abstract}
Öz
Pedagojik alan bilgisinin bir parçası olarak kabul gören pedagojik muhakeme kavramının nasıl ölçüleceği hakkında fen eğitimi araştırmaları camiası fikir birliğine ulaşamamıştır. Bu konuyu adres gösteren erken bir hamle niteliğindeki bu araştırmanın amacl; kimya öğretmenlerinin pedagojik muhakemelerini kimyasal reaksiyonlarda dengenin doğası konusu ile ilgili bir dersin planlama-öğretme-yansıtma aşamaları boyunca değerlendirmektir. Gözlem öncesi ve sonrası röportajlar ve uyarllmış hatırlama röportajları sayesinde öğretmenlerin öğretim kararları ve öğretme eylemleri esnasında yürüttükleri pedagojik muhakeme hakkında veri toplanmıştır. Öğretmenlerin röportaj sorularına verdikleri cevaplar pedagojik muhakemeyi ölçmek için önerilen değerlendirme ölçütü ile analiz edilmiş ve elde edilen bulgular puanlandırılmıştır. Araştırmanın bulguları, kimya öğretmenlerinin pedagojik muhakeme düzeylerinin yaklaşık yüzde 50 olduğunu göstermektedir. Bu değere en yüksek katkı sağlayan aşama planlama olurken, en düşük katkı sağlayan aşama yansıtma olmuştur. Öğretme ve yansıtma aşamalarında ki pedagojik muhakeme boyutları, program bilgisinden öğrencilerin fen anlamasına doğru azalmıştır. Planlama aşamasındaki pedagojik muhakeme boyutlarında ise önemli bir değiş̧iklik olmamıştır. Katılımcıların toplamda en düşük puanı öğrencilerin fen anlaması boyutundan, en yüksek puanı ise program bilgisi boyutundan aldığı tespit edilmiştir. Kimya öğretmen eğitimi ve pedagojik alan bilgisi ile pedagojik muhakeme araştırmaları için öneriler sunulmuştur.
\end{abstract}

Anahtar Kelimeler: Pedagojik Alan Bilgisi, Pedagojik Muhakeme, Planlama-Öğretme-Yansıtma, Kimya Ö̆̆retimi 


\title{
Evaluation of Chemistry Teachers' Pedagogical Reasoning Throughout the Cycle of Instruction
}

\begin{abstract}
Being regarded as a part of pedagogical content knowledge, science education research community has not reached a consensus about the ways how to measure pedagogical reasoning. As an early attempt to address that issue, the aim of this research is to evaluate chemistry teachers' pedagogical reasoning during planning-teaching-reflecting parts of a lesson related to nature of equilibrium in chemical reactions. Data on pedagogical reasoning that underlies teachers' instructional decisions and teaching actions were collected by pre- and post-observation interviews and stimulated recall interviews. Responses that teachers gave to interview questions were analyzed by evaluation criteria suggested to measure pedagogical reasoning, and results were scored accordingly. Results of this research show that the extent of chemistry teachers' pedagogical reasoning is nearly 50 percent. As planning is the part that contributes the most to that value, reflecting is the part that contributes the least. Pedagogical reasoning dimensions in teaching and reflecting decreased from curriculum saliency to students' understanding of science. However, pedagogical reasoning dimensions in planning did not show an important change. The lowest score gained by participants was students' understanding of science dimension, and the highest one was the dimension of curriculum saliency. Recommendations for chemistry teacher education and pedagogical content knowledge and pedagogical reasoning research are presented.
\end{abstract}

Keywords: Pedagogical Content Knowledge, Pedagogical Reasoning, Planning-TeachingReflecting, Chemistry Teaching 


\section{Giriş}

Eğitim araştırmalarına pedagojik alan bilgisi (PAB) (pedagogical content knowledge) kavramını kazandıran Shulman (1986, 1987), bu yapının, öğretmenleri alan uzmanlarından ayırdığını ve nitelikli bir öğretim için gerekli bir mesleki bilgi kategorisi olduğunu savunmuştur. $\mathrm{PAB}^{\prime}$ in bir bilgi temelinden eyleme dönüşmesi için pedagojik muhakeme (PM) (pedagogical reasoning) adı verilen anlamlandırma sürecinden geçmesi gerektiğini belirten Shulman (1987), bu süreçte öğretmenlerin, öğretme eylemleri ve öğretim kararları ile ilgili muhakeme yapmalarının önemine değinmiştir. Baxter ve Lederman (1999) da "bir öğretmenin ne bildiği, ne yaptığ1 ve eylemleri için gerekçelerinin" PAB'ı oluşturduğunu belirterek, PM'nin $\mathrm{PAB}^{\prime}$ in bir parçası olduğu fikrini desteklemişlerdir (s.158).

PM'nin PAB kavramı içerisindeki yeri daha sonraki yıllarda önerilen pek çok PAB modelinde de farklı isimlendirmeler ile karşımıza çıkmaktadır. Bu duruma, pentagon modeli (Park ve Oliver, 2008) örnek verilebilir. $\mathrm{Bu}$ model; nitelikli $\mathrm{PAB}$ 'a sahip olmak için $\mathrm{PAB}$ bileşenlerinin bireysel gelişiminin yeterli olmadığını, bu bileşenler arasında uyumlu, tamamlayı$\mathrm{Cl}$, sürekli ve eş zamanlı etkileşimlerin de olması gerektiğini savunur. Bu etkileşimlerin, "öğretim sırasındaki yansıtma" (reflection-in-action) ve "öğretimden sonraki yansıtma" (reflection on action) (Schön, 1987) süreçleri ile sağlandığın belirtir. Pentagon modelinde belirtilen bu süreçler, nitelikli $\mathrm{PAB}^{\prime}$ a sahip olmak için öğretmenlerin PM ile meşgul olmaları gerektiğine vurgu yapmaktadır (Park ve Suh, 2019).

Tarihi bir geçmişe sahip olan PM'nin PAB içerisindeki rolü, fen eğitimi bağlamında önerilen en güncel PAB modeli olan Refined Consensus model (RCM) (Hume, Cooper, ve Borowski (Eds.), 2019) ile kuvvetlice bir kez daha doğrulanmıştır. Şekil 1'den görüleceği üzere, bu modelin deseninde iç içe geçmiş daireler ve çift yönlü oklar kullanılmıştır. Bu sayede, fen öğretimi uygulamalarının ve bir dersi planlama-öğretme-yansıtma esnasında yürütülen PM'nin merkezde yer almasına verilen önem ve farklı bilgi ve beceri türleri arasında gerçekleşen alış veriş vurgulanmıştır. RCM'nin PAB alan yazınına kazandırdığı en önemli özellik, üç farklı PAB türünü kavramsallaştırmasıdır (Carlson ve Daehler, 2019). En diştan merkeze doğru; "ortak PAB" (oPAB) (collective PCK), "kişisel PAB" (kPAB) (personal $\mathrm{PCK}$ ) ve "temsili PAB" (tPAB) (enacted PCK) şeklinde çeşitli PAB'lar ko- 
numlandırılmıştır. oPAB; "bir alanda birçok eğitimcinin sahip olduğu özelleşmiş mesleki bilgiyi", $\mathrm{kPAB}$; "fen alanında bir öğretmenin sahip olduğu bireysel mesleki bilgiyi", tPAB; "öğretmenin bir dersi planlama, öğretme ve yansıtma esnasında pedagojik muhakeme içinde bulunması için gerekli olan bilgiyi" tanımlar (Carlson ve Daehler, 2019, s.82).

Carlson ve Daehler (2019), "öğretmenlerin pedagojik muhakemeleri üzerine yapılan araştırmaların değerini" ilan ederken (s.81); Park ve Suh (2019), RCM modelinin "pedagojik muhakeme incelemek için faydalı bir araç" olduğunu belirtmiştir (s.195). Chan, Rollnick ve Gess-Newsome (2019) ise PM'nin PAB'in bir parçası olarak değerli olduğunu ancak PM'nin nasıl ölçüleceği hakkında fen eğitimi araştırmaları camiasının fikir birliğine ulaşamadığını paylaşmıştır. Bu araştırma, bu konuyu adres gösteren erken bir hamle niteliğindedir.

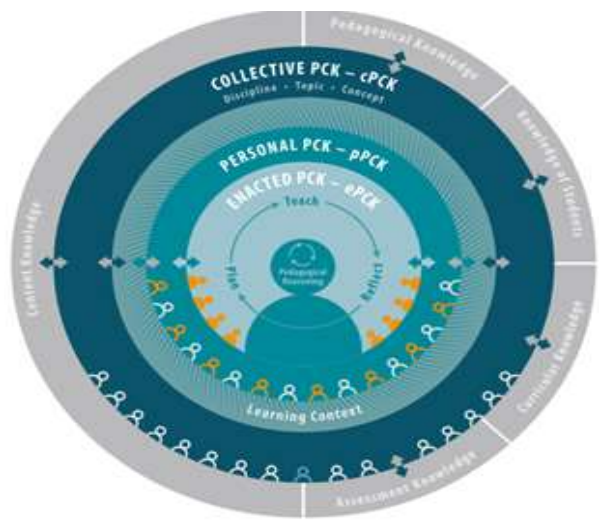

Şekil 1. RCM Modeli'nin Grafiksel Gösterimi (Carlson ve Daehler, 2019, s.83)

Uluslararası bağlamda PAB çalışmaları yürüten pek çok fen eğitimi araştırmacısının en güncel fikirleri derlenerek sunulan RCM modeline dayanarak yapılan bu araştırmada, modelin merkezi mercek altına alınmıştır. Bir öğretmenin, planlama-öğretme-yansitma esnasında gerçekleştirdiği eylemler ve aldığı öğretim kararlarının arkasında yatan sebeplere ulaşılmasını sağlayan PM (Carlson ve Daehler, 2019), bu çalışmada çok boyutlu bir yapı olarak ele alınmıştır. Alonzo, Berry ve Nilsson'ın (2019) temsili PAB'ı boyutlandırmasına benzer şekilde (ePCK, $\left.\mathrm{ePCK}_{\mathrm{T}}, \mathrm{ePCK}\right)$, bu araştırmada da PM; PMr, PMö ve PMr olarak kavramsallaştırılmıştır. PMö; öğretme eylemi sıra- 
sında alınan anlık kararlar ile ilgili PM'yi temsil ederken, PMP ve PMr; sırasıyla, planlama ve yansitma esnasında alınan kararlar ile ilgili PM'yi temsil etmektedir. Özetle, bu çalışmada, kimya öğretmenlerinin pedagojik muhakemelerini öğretim döngüsü boyunca değerlendirmek amaçlanmıştır. Bu amaca ulaşmak için belirlenen araştırma sorusu şu şekildedir; kimya öğretmenlerinin kimyasal reaksiyonlarda dengenin doğası konusu ile ilgili pedagojik muhakeme düzeylerine öğretim döngüsü aşamalarının (PMP, PMö, $\mathrm{PMr)} \mathrm{katkısı} \mathrm{ne} \mathrm{düzeydedir?}$

\section{Yöntem}

\section{Araştırma Yöntemi}

Kimya öğretmenlerinin bir dersin planlama, öğretme, yansıtma aşamaları boyunca PM'lerini belirlemeyi amaçlayan bu çalışma bir tarama araştırmasıdır. Büyüköztürk ve ark. (2010), tarama araştırmalarını; "bir grubun belirli özelliklerini belirlemek için verilerin toplanmasını amaçlayan çalışmalar" olarak tanımlamışlardır (s.16). Tarama araştırmalarında kullanılan veri toplama yöntemlerinden birisi olan yüz yüze görüşmeler (Fraenkel ve Wallen, 2006) yapılarak katılımcıların PM'leri ile ilgili veriler bir seferde toplanmıştır. Bu açıdan, tarama araştırma türlerinden kesitsel araştırma kategorisinde yer almaktadır (Fraenkel ve Wallen, 2006). Nicel araştırmalar olarak sınıflandırılan tarama araştırmalarının amacına uygun şekilde; bu çalışmada, kimya öğretmenlerinin PM'lerinin ne düzeyde olduğu öğretim döngüsü boyunca betimlenmiştir.

\section{Çalışma Grubu}

Örneklem belirleme aşamasında belirleyici olan temel unsur; araştırılması planlanan kimya konusu olmuştur. Öğretmenlerin PM'lerini incelemek için kimyasal denge konusunun seçilmesinin sebepleri; bu konunun soyut bir doğasının olması ki bu sebeple öğrenciler kavramları anlamakta zorluk yaşamaktadırlar (Mavhunga, 2018) ve diğer kimya konuları için temel oluşturmasıdır (örn; asitler ve bazlar) (Milli Eğitim Bakanlığı [MEB], 2018). Bu araştırmada, basit seçkisiz örnekleme yöntemi (Fraenkel ve Wallen, 2006) kullanılmıştır. Bir şehir merkezinde, 2018-2019 eğitim-öğretim yılının ikinci 
döneminde 11. sınıf öğrencilerinin (17-18 yaş) kimya derslerine giren öğretmenler belirlenerek (kimyasal denge ünitesi 11. sınıf programında yer aldığ 1 için), araştırma ile ilgili bilgi verilmiştir. Diğer bir ifadeyle, bahsedilen koşullara sahip olan bütün kimya öğretmenlerinin bu araştırmaya katılmasına eşit seçilme ihtimali verilmiştir. Görüşülen öğretmenlerin arasından gönüllü olanlar araştırmaya katılmak istediklerine dair izin formu imzalamıştır. Sonuç olarak, 53 kimya öğretmeni araştırmanın örneklemini oluşturmuştur. Katılımcların 15'inin öğretmenlik deneyimi beş yıldan daha kısa iken 38 'inin deneyimi beş yıldan daha uzundur. 45 katılımcı devlet okullarında öğretmenlik yaparken, diğer sekizi özel okullarda görev yapmaktadır. Öğretmenlerin tamamı, görev yaptıkları okullar dikkate alınmaksızın, kimya dersi ögretim programını referans almaktadırlar.

\section{Verilerin Toplanması}

Veri toplama yöntemi olarak, Chan ve Hume (2019) tarafından önerilen "gerçek hayat öğretimleri" yaklaşımı benimsenmiştir (s. 20). PAB belirlemeye yönelik önerilen bu yaklaşımın iki şekilde benimsenebileceği belirtilmiştir. Bunlar; "sadece öğretme ürünleri/öğretme eylemi inceleyen çalışmalar" ve "öğretmenlerin öğretim kararlarını da inceleyen çalışmalar" dır (s.17). İkinci kategori kendi içerisinde; "simüle edilmiş öğretim işleri" ve "gerçek hayat öğretimleri" olarak iki alt kategoriye ayrılmaktadır. Gerçek hayat öğretimleri yaklaşımını benimseyen araştırmalarda; öğretmenlerin karar verme süreçlerinin açık uçlu sorulardan oluşan röportajlar ile otantik gerçek hayat bağlamlarında ve öğretim döngüsü boyunca veri toplayacak şekilde planlanması önerilmektedir (Chan ve Hume, 2019). Bu doğrultuda, bu araştırmada; gözlem öncesi ve sonrası röportajlar ve uyarılmış hatırlama röportajları sayesinde öğretmenlerin öğretim kararları ve öğretme eylemleri esnasında yürüttükleri pedagojik muhakemeleri hakkında veri toplanmıştır. Tablo 1, bu araştırmada verilerin nasıl toplandığı ile ilgili bilgi sunmaktadır. 
Tablo 1. Veri Toplama Süreci

\begin{tabular}{lll}
\hline Veri Kaynağı & Amacı & Zamanlaması \\
\hline Gözlem öncesi röportajlar & $\begin{array}{l}\text { Planlama aşamasındaki PM } \\
\text { verisini toplamak }\end{array}$ & İlgili dersten birkaç gün önce \\
$\begin{array}{l}\text { Gözlem sonrası röportaj- } \\
\text { lar }\end{array}$ & $\begin{array}{l}\text { Yansıtma aşamasındaki PM } \\
\text { verisini toplamak }\end{array}$ & İlgili dersten birkaç gün sonra \\
$\begin{array}{l}\text { Uyarılmış hatırlama } \\
\text { röportajları }\end{array}$ & $\begin{array}{l}\text { Öğretme aşamasındaki PM } \\
\text { verisini toplamak }\end{array}$ & İlgili dersten iki hafta sonra \\
\hline
\end{tabular}

Not: Katılımcıların aynı zamanda belirlenen konuyu işlemeleri sebebi ile bazıları ile bir gün, diğerleri ile iki gün önce/sonra röportaj yapılabilmiştir

Öğretmenlerin aynı zamanlarda kimyasal reaksiyonlarda dengenin doğası konusunu işlemesi sebebiyle ders gözlemleri araştırmacı tarafından yapılamamıştır. Ancak, derslerin video ile kayıt edilmeleri sağlanmıştır. Derslerin fiziksel olarak sınıf içinde gözlenmesi ile kıyaslanacak olursa video ders kayıtlarının birçok üstünlüğü bulunmaktadır. Tekrar izleme fırsatı vermesi, araştırmacının not almak için acele etmesine gerek kalmaması ve sınıfta olan olayların tamamını ham bir veri olarak sunması video ders kayıtlarının üstün yönlerine örnek verilebilir (Carpandale, 2018; Simpson ve Tuson, 2003). Bir öğretmenin öğretme eylemine şahit olmak onun neden bu pedagojik tavırları sergilediği ile ilgili bir çıkarım yapılmasını sağlasa da, PM'sını değerlendirmek için yeterli bir veri kaynağı değildir (Alonzo ve ark., 2019; Chan ve ark., 2019). Bu sebeple, ders gözlemlerinin video kayıtları bu araştırmanın veri kaynaklarından değildir. İlgili alan yazın öğretmenlerin PM'larına ulaşmak amacıyla ders gözlemleri yerine uyarılmış hatırlama röportajları (stimulated recall interviews) (UHR) yapılabileceğini belirtmektedir. UHR; "öğretmenlerin düşünceleri, kararları ve eylemleri için muhakemelerini (yani pedagojik muhakemelerini) incelemek için etkili bir tekniktir" (Park ve Suh, 2019, s.194). Kimya öğretmenlerinin PM'lerini ölçmeyi hedefleyen bu araştırmada, ders gözlemlerinin video kayıtları düzenlenmiş ve UHR'lerde kullanılmak üzere öğretim materyallerine (teaching artefacts) dönüştürülmüştür. Diğer bir ifadeyle, ders gözlemlerinin video kayıtlarının düzenlenmesi ile oluşturulan öğretim materyalleri, bu çalışmada kullanılan bir veri toplama aracıdır.

Bazı öğretme anlarını (örn; beklenmeyen bir öğrenci fikri) dikkate alarak oluşturulan öğretim materyalleri UHR esnasında öğretmenlere izlettirilmiş (kendi öğretimleri ile ilgili olanlar) ve onlardan, bu anı (örn; öğrenci fikri) tanımlamaları ve o anda neden o tavrı/cevabı (örn; örnek sunması) 
verdiklerini açıklamaları istenmiştir. Tamamlayıcı sorular vasıtasıyla röportajlar devam ettirilmiştir. Örneğin; bu soruyu bekliyor muydunuz? Bu şekilde cevap vermeye nasıl karar verdiniz? Cevabınız işe yaradı mı? Neden? Cevabınızın işe yaradığını nasıl anladınız? Katılımcı öğretmenler ile bireysel olarak yürütülen her bir SRI yaklaşık bir saat sürmüştür. Gözlem öncesi ve sonrası röportaj soruları hazırlanırken ilgili alan yazından faydalanılmıştır (örn; Park, Jang, Chen, ve Jung, 2011). Örnekler, Tablo 2'de sunulmuştur. Öğretmenlerin, gözlem öncesi ve sonrası röportajları ve UHR sorularına verdikleri sözlü cevapların ses kayıtları alınmıştır.

\section{Verilerin Analizi}

Röportajlar ile toplanan veriler öncelikle yazı haline dönüştürülmüştür. Chan ve ark. (2019) tarafından PAB'ın niteliğini ölçmek amacıyla geliştirilen "Grand Rubric" isimli rubriğin PM'yi ölçmek için önerilen bölümü, araştırma ile toplanan verilerin analizini sağlayacak şekilde adapte edilmiştir. Grand Rubric'te PM'nin değerlendirme ölçütü; “öğretmenlerin kendi öğretme durumlarında aldıkları kararlar ve eylemler için mantıklı açıklama sağlaması" (s. 264) şeklinde sunulmuştur. Değerlendirme ölçütünün bu araştırmada ki operasyonel tanımlaması; "bir öğretmenin, kimyasal reaksiyonlarda dengenin doğası konusu ile ilgili öğretme eylemleri ve öğretim kararlarını program bilgisi, kavramsal öğretme stratejileri ve öğrencilerin fen anlaması boyutlarında açıklaması ve muhakeme etme becerisi" şeklinde belirtilebilir. Program bilgisi (curricular saliency) (PB), kavramsal öğretme stratejileri (conceptual teaching strategies) (KÖS) ve öğrencilerin fen anlaması (students' understanding of science) (ÖFA), bu araştırmada öğretmenlerin PM'lerini ölçmek için kullanılan boyutlardır. Bu boyutlar, Chan ve ark. (2019) tarafından önerilen PAB bileşenleridir ve röportajlarda ki sorular bu boyutlar dikkate alınarak hazırlanmıştır. Örneğin; Tablo 2'de ki "konu ile ilgili öğrencilerin hangi kavramları öğrenmesinin önemli olduğunu düşünüyorsunuz? Neden?" sorusu, öğretmenlerin PB ile ilgili PMp'leri hakkında veri sağlamıştır. ÖFA ile ilgili PMr hakkında veri toplamak için, örneğin, "konu ile ilgili tahmin etmediğiniz kavram yanılgıları ile karşılaştınız mı? Beklemediğiniz bu kavram yanılgılarına nasıl bir cevap verdiniz? İşe yaradı mı? İşe yaradığını nasıl anladınız?" gibi sorular sorulmuştur. 
Tablo 2. Röportaj Sorusu Örnekleri

Gözlem Öncesi Gözlem Sonrası

- $\quad$ Dersi planlarken ne gibi şeyleri dikkate aldınız?

- Konu ile ilgili öğrencilerin hangi kavramları öğrenmesinin önemli olduğunu düşünüyorsunuz? Neden?

- Konu ile ilgili öğrencilerin öğrenmekte zorluk yaşayacağını tahmin ettiğiniz kavramlar var mı? Hangileri? Neden?

- Konu ile ilgili olası kavram yanılg1larının farkında mısınız? Ne tür kavram yanilgiları var?

- $\quad$ Bu kavramları gidermeleri için öğrencilere nasıl yardımc olmayı planl1yorsunuz? Neden?

Park, Suh ve Seo'nun (2018) çalışmalarında kullandıkları puanlama rubriği, analizi yapılan verilerin puanlandırılması için kullanılmıştır. Park ve ark.'nın (2018) puanlandırma rubriğini bu araştırma ortamına adapte etmek için bazı küçük değişiklikler yapılmıştır. Örneğin; orijinal rubrikte "yeterli" olan kategori, PAB alan yazını ile aynı terminolojiyi kullanmak için bu araştırmada "mükemmel" adını almıştır (örn; Chan ve ark., 2019). Kategorilerin tanımında, orijinal rubrikte "fikir(ler)" geçerken, bu çalışmada "eylemler" de tanımlara eklenmiştir. İlaveten, kategorilerin adlarını belirterek çalışmalarının bulgularını sunan Park ve ark.'ndan (2018) farklı olarak, bu çalışmada, kategoriler puanlandırılmıştır. Tablo 3'ten görüleceği üzere, "sınırlı" sıfır puan, "makul" bir puan ve "mükemmel" iki puan sağlamaktadır.

\section{Tablo 3. Puanlandirma Rubriği}

\begin{tabular}{ll}
\hline Kategori & Tanım \\
\hline Sınırlı & Öğretmen, fikirleri ve eylemleri için ne açıklamada bulunmuş ne de gerekçeler \\
(0 puan) & sunmuştur; basitçe fikirlerini yinelemiştir. \\
Makul & Öğretmen, fikirleri ve eylemleri için ya açıklamada bulunmuş ya da muhake- \\
(1 puan) & me yapmıştır; fikirlerini detaylıca açılamış veya gerekçelerini sunmuştur. \\
Mükemmel & Öğretmen, fikirleri ve eylemleri için hem açılamada bulunmuş hem de mu- \\
(2 puan) & hakeme yapmıştır; fikirlerini detaylıca açılamış ve gerekçelerini sunmuştur. \\
\hline
\end{tabular}

Not: (Park ve ark. (2018), s. 569) 


\section{Bulgular}

Kimya öğretmenlerinin kimyasal reaksiyonlarda dengenin doğası konusu ile ilgili pedagojik muhakeme düzeylerine öğretim döngüsü aşamalarının (PMr, PMö, PMr) katkısı ne düzeydedir? sorusuna cevap bulmak için toplanan verilerden elde edilen betimleyici istatistik bulgularına aşağıda yer verilmiştir.

Araştırmanın veri setini 53 kimya öğretmeninden bireysel olarak toplanan veriler oluşturmaktadır. Bu çalışmada, bir katılımcının PM'si araştırılırken; PMP, PMö ve PMr aşamaları ve her bir aşamadaki PB, KÖS ve ÖFA boyutları ele alınmıştır. PM boyutlarının birisinden (örn; PB) alınabilecek en düşük değer sıfır, en yüksek değer iki puan olduğuna göre (Bkz. Tablo 3) bir katılımcının bir PM aşamasından (örn; PMP) alabileceği en yüksek puanın 6 olduğu hesaplanabilir. Öğretim döngüsünün tamamı dikkate alındığında ise bir katılımcının toplam PM puanının sıfır-18 puan aralığında yer alacağı bilinmektedir. Bireysel veriler incelendiğinde, alınan en düşük PM puanının $1(\mathrm{f}=2)$, en yüksek PM puanının ise $18(\mathrm{f}=1)$ olduğu tespit edilmiştir.

Bu bölümünün buradan sonraki kısımlarında katılımcların toplam puanları üzerinden elde edilen bulgular rapor edilmiştir. Şekil 2, planlamaöğretme-yansıtma aşamalarında katılımcıların her bir PM boyutundan aldıkları puanları ve toplamını göstermektedir. Öğretmenlerin; PMP aşamasının PR boyutundan 62 puan, KÖS boyutundan 67 puan ve ÖFA boyutundan 71 puan; PMö aşamasının PB boyutundan 62 puan, KÖS boyutundan 54 puan ve ÖFA boyutundan 43 puan; PMr aşamasının PB boyutundan 57 puan, KÖS boyutundan 42 puan ve ÖFA boyutundan 30 puan aldıkları görülmektedir. Diğer bir ifadeyle, planlama aşamasında ki PM boyutları PS'den ÖFA'ya doğru az da olsa artış gösterirken, öğretme ve yansıtma aşamalarında ki PM boyutları aynı yönde azalış göstermektedir. PM aşamalarından alınan toplam puanlar da planlama-öğretme-yansıtma sırasıyla $(200,159,129)$ azalmıştır. 


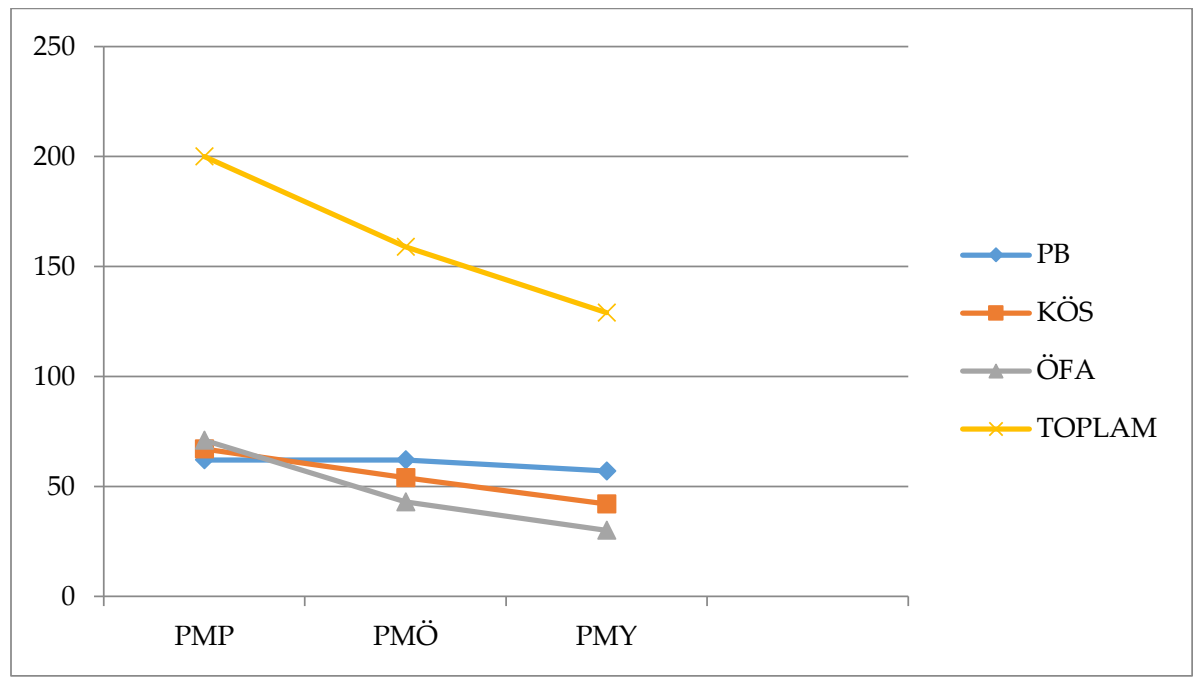

\section{Şekil 2. Öğretim Döngüsü Boyunca PM}

Not: PMp: planlama aşamasındaki pedagojik muhakeme; PMö: öğretme aşamasındaki pedagojik muhakeme; PMr: yansıtma aşamasındaki pedagojik muhakeme; PR: program bilgisi; KÖS: kavramsal öğretme stratejileri; ÖFA: öğrencilerin fen anlamast

Şekil 2'den PM boyutları temelinde bir inceleme de yapılabilir. Şöyle ki; her bir PM boyutunun, planlama-öğretme-yansıtma aşamalarında ki puanları toplanabilir. PB boyutunda PMP, PMö ve PMr aşamalarından alınan puanların toplamının 181; KÖS boyutunda PMP, PMö ve PMy aşamalarından alınan puanların toplamının 163; ÖFA boyutunda PMP, PMö ve PMY aşamalarından alınan puanların toplamının 144 olduğu görülmektedir. Katılımcıların en düşük ÖFA, en yüksek PB boyutunda PM puanı aldığı tespit edilmiştir.

PMP, PMö ve PMr aşamalarından alınan toplam puanların katılımcıların PM düzeyine katkısını tespit etmekte kullanılabilecek diğer gösterimlere Tablo 4 ile ulaşılabilmektedir. Her bir PM boyutu için bir katılımcının alabileceği puanın sıfır ile iki aralığında değişmesi, veri setinde aykırı bir değer bulunmadığının ispatıdır. Bu sebeple, verilerin gösteriminde ortalamadan faydalanılmıştır. Bir diğer gösterim şeklinde de yüzde değerler hesaplanmıştır. Planlama aşamasında ki PM boyutlarının PB'den ÖFA'a doğru az da olsa artış gösterdiği bulgusu, ortalama ve yüzdeler olarak ifade edildiğinde görülüyor ki PMp'nin boyutları yaklaşık değerlere sahip- 
tir. Ancak PMö ve PMr aşamalarında ki boyutlarda PB'den ÖFA'ya doğru puan azalışı, ortalama ve yüzdelerden de tespit edilebilmektedir.

Tablo 4'te sunulan bilgilere ek olarak, katılımcların her bir PM aşamasında ki ortalama ve yüzdeleri de hesaplanabilir. PB, KÖS ve ÖFA boyutlarından alının puanlar toplamı katılımcı sayısına bölündügü zaman görülüyor ki; en yüksek ortalama planlama (ortalama: 3.8; yüzde: 41.0) aşamasından alınmıştır. Planlamayı, öğretme (ortalama: 3.0; yüzde: 33.0) ve yansıtma (ortalama: 2.4; yüzde: 26.0 ) aşamaları takip etmiştir.

Tablo 4. Katılımcılarn Öğretim Döngüsü Boyunca PM Boyutları Temelinde Ortalama ve Yüzde Değerleri

\begin{tabular}{llllllllll}
\hline & PMP & \multicolumn{3}{c}{ PMö } & \multicolumn{3}{c}{ PMr } \\
\cline { 2 - 9 } & PB & KÖS & ÖFA & PB & KÖS & ÖFA & PB & KÖS & ÖFA \\
Ortalama & 1.2 & 1.3 & 1.3 & 0.8 & 1.0 & 1.2 & 0.6 & 0.8 & 1.1 \\
Yüzde & 12.7 & 13.7 & 14.6 & 9.0 & 11.3 & 12.7 & 6.1 & 8.6 & 11.3 \\
\hline
\end{tabular}

Son olarak, katılımcların öğretim döngüsü boyunca PM aşamalarında ki toplam puan değerlendirilebilir. Bir PM boyutundan en yüksek iki puan alındığı ve 53 katılımcının yer aldığı dikkate alınarak tüm aşamalarda ki tüm boyutlar hesaplandığında; alınabilecek en düşük puanın sıfır iken en yüksek puanın 954 olduğu bulunur. Katılımcların toplam PM puanı ise $488^{\prime}$ de kalmıştır. Bu puana karşılık gelen ortalama değer 9.2, yüzde değer ise 51.2 'dir.

\section{Sonuçlar ve Tartışma}

Araştırmanın sonuçları şu şekilde özetlenebilir;

- kimya öğretmenlerinin kimyasal reaksiyonlarda dengenin doğası konusu ile ilgili PM düzeyleri yaklaşık yüzde 50'dir,

- bu düzeye en yüksek katkı sağlayan aşama planlama (PMP) olurken, en düşük katkı sağlayan aşama yansıtma (PMr) olmuştur,

- öğretme ve yansıtma aşamalarında ki PM boyutlarından (PMö ve PMY) program bilgisinde en yüksek puanı alırlarken, öğretmenler bu PM aşamalarında ki öğrencilerin fen anlaması boyutundan ise en düşük puanı almışlardır,

- planlama aşamasında ki PM boyutlarında önemli bir değişiklik olmamıştır, 
- katılımcların toplam PM puanlarına en yüksek katkıyı program bilgisi boyutu yaparken, en düşük katkıyı öğrencilerin fen anlaması boyutu yapmiştır.

Nitelikli bir öğretim için; disiplin, o disipline özgü konular veya o konunun kavramları hakkında öğretmenlerin ne bildiklerinin önemli bir önkoşul olmakla birlikte yeterli koşul olmadığı eğitim araştırmacılarının ortaya koyduğu bir gerçektir (Abell, 2007). Shulman (1987), öğretme eylemleri ve muhakeme olmadığı sürece bir öğretmenin bilgi temellerinin işe yaramayacağını belirtmiştir. Pedagojik muhakeme olarak adlandırdığ 1 bilginin anlamlandırılması sürecine verilen değer diğer PAB araştırmacılarınca da desteklenmiştir. Örneğin, Baxter ve Lederman (1999) tarafından yapılan tanımda görülüyor ki PAB, öğretmenlerin sadece bilgileri ile değil aynı zamanda becerileri ve muhakemeleri ile ilgili bir yapıdır. Diğer bir ifadeyle, yapılacak/yapılan öğretim ve alınan öğretim kararları ile ilgili muhakeme yürütülmesinin bir öğretmenin nitelikli öğretim sunmasına katkı sağlayacağı belirtilmektedir. Park ve ark. (2018), “bir öğretmenin ne bildiği ne yaptığına otomatik olarak yansımaz" (s. 553) şeklinde görüşlerini belirtmiş ve öğretmenlerin bilgilerini öğretme eylemine dönüştürmelerinde "öğretim sırasındaki yansıtma" (reflection-in-action) ve "öğretimden sonraki yansıtma" (reflection on action) (Schön, 1987) süreçlerinin önemine vurgu yapmışlardır. PAB alan yazınında pek çok çalışma yapan Park ve Suh, 2019 yılında ki çalışmalarında; fen eğitimi bağlamında önerilen en son model olan RCM'nin kuramsal çerçevesi doğrultusunda şimdiye kadar elde ettikleri bulguları tekrar gözden geçirmiştir. Park ve Suh (2019), "öğretim sırasındaki yansıtma" ve "öğretimden sonraki yansıtma" süreçlerinin RCM'ye uyum kapsamında PM süreci ile aynı olduğunu ifade etmişlerdir.

Araştırmacıların ulaştıkları sonuçlar referans alınarak, nitelikli kimya öğretimi sağlanmasında öğretmenlerin PM düzeylerinin katkısının yadsınamayacağı söylenebilir. Kimya öğretmenlerinin PM düzeylerinin öğretim döngüsü boyunca değerlendirildiği bu araştırmada, öğretmenlerin PM düzeylerinin yaklaşık olarak yüzde 50 düzeyinde olduğu saptanmıştır. Bu sonuç, bir öğretmenin neden o eylem(ler)i yaptığ ve neden o karar(lar)1 aldığı noktasında yüzde 50 bilinçli olmadığı şeklinde de sunulabilir. PM'nin nitelikli öğretimin bir ölçüsü olarak görülen PAB'nin bir parçası olduğu düşünüldüğünde, katılımclların kimya öğretimlerinin öğrencilerin 
kimya öğrenmesini destekleme noktasında eksik kalacağı tahmin edilebilir. Çünkü planlama-öğretme-yansıtma döngüsü boyunca öğretmenler, öğrencilerin ihtiyaçlarını göz önüne almadan öğretim yapacaktır. Örneğin, hangi durumlarda hangi öğretim yaklaşımlarını işe yaradığını fark etmeyecektir (van Driel, Berry, ve Meirink, 2014).

PM'nin tarihsel kökeni Shulman'a (1987) dayanmasına rağmen bu kavram ile ilgili araştırmaların PAB alan yazınında yaygın olduğu söylenemez. Ancak bu durum, PM kavramına önem verilmediği için değil, PM'nin niteliğini ölçmek konusunda fikir birliğine varılamamış olmasından kaynaklanmaktadır (Chan ve ark., 2019). RCM'nin geliştirilmesinde katkıları olan aktif PAB araştırmacıları, PM'nin PAB'ı oluşturan kavramlardan birisi olduğunu kabul etmekte ve yapılacak PM araştırmalarının $\mathrm{PAB}$ alan yazınına değer katacağına inanmaktadırlar (Carlson \& Daehler, 2019; Chan ve ark., 2019; Park ve Suh, 2019). Fen eğitimi bağlamında önerilen en güncel $\mathrm{PAB}$ modeli olan RCM'nin bu araştırmada olduğu gibi gelecekte yapılacak PM çalışmaları için etkin bir kuramsal çerçeve oluşturacağ tahmin edilmektedir. Bahsedilen sebeplerden dolayı, bu araştırmada ulaşılan sonuçlar PAB alan yazınında rapor edilen diğer çalışmaların sonuçları ile karşılaştırılamamaktadır. Bu araştırma ile ulaşılan sonuçlar kendi arasında tartışılabilir. Kimya öğretmenlerinin PM düzeylerine öğretim döngüsü aşamalarının (PMr, PMö, PMr) ve PM boyutlarının katkısının ne düzeyde olduğu ile ilgili ulaşılan sonuçlara birlikte bakılacak olursa; PM düzeyine en yüksek katkı sağlayan aşamanın planlama olduğu ve bu aşamadaki PM boyutlarının puanlarında önemli bir değişiklik olmadığ görülmektedir. Yansitma aşamasının ise tam tersine PM düzeyine en düşük katkı sağlayan aşama olduğu ve bu aşamadaki PM boyutlarının puanlarında farklılıklar olduğu görülmektedir. Ulaşılan bu sonuçlar, öğretim döngüsünün aşamaları ile PM boyutları arasında bir ilişki olduğunun kanıtı niteliğindedir. Şöyle ki; bir öğretmen, planlama-öğretme-yansıtma aşamalarının tamamında öğretim kararları ve öğretme eylemleri arkasında yatan sebeplerin muhakemesini yaparsa PAB bileşenleri (PB, KÖS, ÖFA) daha bütüncül olmaktadır. PAB bileşenleri arasında etkileşim olması yani bileşenlerin parçalı olmamasının nitelikli bir kimya öğretimine katkı sağladığı bilinmektedir (Aydın ve ark., 2013).

Ögrretme ve yansıtma aşamalarında PM boyutları puanları arasında farklılık olması durumu yakından incelenecek olursa; en yüksek puanın 
program bilgisinden, en düşük puanın ise öğrencilerin fen anlamasından alındığı görülmektedir. Bu sonuç öğretmenlerin PM'sine en yüksek katkı sağlayan aşamanın planlama olması ile birleştirilirse; bir öğretmenin, kimya dersi öğretim programını temel alarak planladığı bir derste öğrencilerin fen anlaması ile ilgili öğretim anlarını tamamıla planlayamayacağı anlaşılabilir. Diğer bir ifadeyle, anlatacakları kimya konusu ile ilgili öğretmenlerin öngöremeyecekleri birçok öğrenci anlaması olabilmektedir. Farklı ilgi ve ihtiyaçlara, kavram yanılgılarına sahip öğrenciler gibi. Aslında bu sonuç şaşırtıcı değildir. Çünkü öğrenci özellikleri öğrenme ortamının önemli bir boyutudur (Carlson ve Daehler, 2019). "Fen öğretimi öğrencilere ve ortama duyarlıdır, dolayısıyla her sınıf ortamı diğerlerinden (az da olsa) biraz farklıdır" (Alonzo ve ark., 2019, s.273). Öğretmen bilgisinin sınıf içine bir kısmının aktarıldığı ve bilgi aktarımının öğrenme ortamına göre şekilleneceği, RCM'in kişisel $\mathrm{PAB}$ ve temsili $\mathrm{PAB}$ şeklinde farklı $\mathrm{PAB}$ türleri önermesini destekler niteliktedir. Özetle, bu araştırma ile ulaşılan sonuçların RCM modelinde önerilen kavramları desteklediği söylenebilir.

\section{Öneriler}

$\mathrm{Bu}$ araştırma ile ulaşılan sonuçlardan yola çıarak öğretmen eğitimcilerine önerilerde bulunulabilir. Örneğin; nitelikli bir kimya öğretimi için öğretmen adaylarını, öğretim döngüsünün tüm aşamalarında deneyim kazandıracak uygulamalarla tanıştırmak gerekmektedir. Öğretmenlik uygulaması gibi derslerde öğretmen adaylarının sadece öğretimini değil aynı zamanda planlama ve yansıtma aşamalarında ne yaptıklarını da değerlendirmek önemlidir. Öğretmenliğin, sınıf içerisinde anlık kararlar verilmesini gerektiren bir meslek olduğu gerçeği bu araştırmanın sonuçları ile de doğrulanmaktadır. Bu sebeple; öğretmen eğitimcilerine, öğretmen adaylarını mümkün olduğunca fazla kimya konusunun yaygın kavram yanılgıları hakkında bilgilendirmesi ve öğrencilerin zorlandıkları veya yanılgıya sahip oldukları bu kavramların bilimsel olarak doğru kavramlara dönüştürülmesi için kullanabilecekleri birçok kavramsal öğretim stratejileri ile tanıştırmaları önerilebilir.

Uluslararası, güncel fen PAB alan yazını PM çalışmaları yapılması yönünde çağrıda (örn; Carlson ve Daehler, 2019; Park ve Suh, 2019) bulunmakla birlikte PM'nin nasıl ölçüleceği hakkında fikir birliği belirtmemiştir. 
Bu sebeple, alan yazında PM ile ilgili henüz iyi örnekler ile karşılaşılmamıştır. Bu konuyu adres gösteren erken bir hamle niteliğinde ki bu araştırmanın birçok yönden bilimsel değeri olduğu düşünülmektedir. Bu alanda yapılacak gelecek çalışmaların öncelikle PM'nin ölçülmesi temasını hedeflemesi önerilebilir. PM araştırmalarına farklı yöntemsel çerçeveler ile yaklaşılması önerilebilir. Örneğin; bu araştırmadaki nicel bulgulara ek olarak, röportaj alıntıları ile nitel boyut kazandırarak karma desen araştırma yapan çalışmaların PM ile ilgili derinlemesine bilgi sunacağı düşünülmektedir. PMP, PMö, PMr aşamaları arasında ki ilişkinin incelendiği bir çalışmanın da alana katkı sağlaması açısından önemli olacağı düşünülmektedir. PM'nin PAB'deki rolünü araştıran çeşitli araştırma türlerinde ki gelecek çalışmalar öğrencilerin kimyayı nasıl daha iyi öğrenecekleri hakkında bilgilendirici olacaktır. 


\title{
EXTENDED ABSTRACT
}

\section{Evaluation of Chemistry Teachers' Pedagogical Reasoning Throughout the Cycle of Instruction}

\author{
Hatice Belge Can \\ Burdur Mehmet Akif Ersoy University
}

Being viewed as a part of pedagogical content knowledge (PCK), pedagogical reasoning (PR) was defined as a complicated process that involves the translation of knowledge to action. Although PR has not been conceptualized recently, it becomes a popular research theme by the introduction of the Refined Consensus Model (RCM) of PCK. This model reaffirms the role of PR within the PCK and calls for research on teachers' pedagogical reasoning. However, certain aspects of research related to PR should be clarified, such as methodological issues. Science education researchers have not reached a consensus about the ways how to measure PR. While addressing that issue, this research defines PR operationally as; a teacher's explanations and reasoning skills in his/her teaching actions and instructional decisions related to the nature of equilibrium in chemical reactions topic by taking the dimensions of curriculum saliency, conceptual teaching strategies and students' understanding of science into account throughout the whole instructional cycle. Collectively, the aim of this research is to evaluate chemistry teachers' pedagogical reasoning during planningteaching-reflecting parts of a lesson related to nature of equilibrium in chemical reactions. The corresponding research question is; what is the extent of contribution of instructional cycle parts (PRPlanning, PRTeaching, PRReflecting) to chemistry teachers' pedagogical reasoning in the topic of the nature of equilibrium in chemical reactions?

Method: Sample of the study is composed of 53 chemistry teachers in varying years of experience in teaching profession and in different school contexts. Data on PR that underlies teachers' instructional decisions and teaching actions were collected by pre- and post-observation interviews and stimulated recall interviews (SRIs). While pre-observation interviews were conducted just before teaching the topic of interest to collect data on 
PR related to planning, post-observation interviews were done after the enacted lesson to collect data on PR related to reflecting. SRIs, on the other hand, were organized two weeks after the enacted lesson to collect data on PR related to teaching. Responses that teachers gave to interview questions were analyzed by evaluation criteria suggested to measure PR, and results were scored accordingly by a scoring rubric. This scoring guide is made up of three categories, namely limited, moderate and sound. These categories provide zero, one and two points, respectively. A teacher was assigned to the limited category when he/she provides neither elaboration nor reasons for his/her ideas and actions; to the moderate category when he/she provides either elaboration or reasons for his/her ideas and actions; to the sound category when he/she provides both elaboration and reasons for his/her ideas and actions.

Conclusions: When individual scores of participants were analyzed, it was found that the lowest score was $1(\mathrm{f}=2)$, and the highest score was $18(\mathrm{f}=1)$ in terms of their total PR score, i.e. from all of the parts and dimensions of PR. The remaining parts of results section belong to teachers' collective scores. The followings summarize results of this section;

- the extent of chemistry teachers' PR is nearly 50 percent,

- planning is the part that contributes the most but reflecting is the part that contributes the least to that extent of PR,

- PR dimensions in teaching and reflecting decreased from curriculum saliency to students' understanding of science,

- PR dimensions in planning did not show an important change,

- the lowest total score gained by participants was students' understanding of science dimension, and the highest one was the dimension of curriculum saliency.

Discussion and Recommendations: It can be readily stated that the contribution of the extent of PR to qualified chemistry teaching cannot be denied. With this study that explores chemistry teachers' PR throughout the instructional cycle, the extent of teachers' PR are found about 50 percent. This conclusion can be restated as a teacher is 50 percent not conscious in terms of why he/she does that action and takes that decision. When PR is thought as a part of PCK which is viewed as a measure of qualified teach- 
ing, it can be expected that participants' chemistry teaching remains insufficient in terms of supporting students' chemistry learning. Because teachers will teach without taking student needs into account throughout planning-teaching-reflecting cycle. For example, he/she will not realize which teaching approach works in which situations.

Recommendations for pedagogical content knowledge and pedagogical reasoning research within the context of chemistry education are as follows; studies that aim to measure sound PR, studies that approach to the field by various methodological frameworks like; the relationships among the cycles of instruction, and studies that search for understanding the role of PR in PCK.

\section{Kaynakça / References}

Abell, S. K. (2007). Research on science teacher knowledge. In S. K. Abell ve N. G. Lederman (Ed.), Handbook of research on science education (s. 1105-1149). Mahwah: Lawrence Earlbaum Associates.

Alonzo, A. C., Berry, A., ve Nilsson, P. (2019). Unpacking the Complexity of Science Teachers' PCK in Action: Enacted and Personal PCK. In A. Hume, R. Cooper ve A. Borowski (Ed.), Repositioning pedagogical content knowledge in teachers' knowledge for teaching science (s. 271-286). Singapore, Springer.

Aydın, S., Demirdöğen, B., Tarkın, A., Kutucu, S., Ekiz, B., Akın, F. N., Tüysüz, M., ve Uzuntiryaki, E. (2013). Providing a set of Researchbased practices to support preservice teachers' long-term Professional development as learners of science teaching. Science Education, 97, 903-935.

Baxter, J. A., ve Lederman, N. G. (1999). Assessment and measurement of pedagogical content knowledge. In J. Gess-Newsome ve N. G. Lederman (Eds.), Examining pedagogical content knowledge (s. 147-161). Dordrecht: Kluwer Academic Publishers.

Büyüköztürk, Ş., Kılıç-Çakmak, E., Akgün, Ö. E., Karadeniz, Ş., ve Demirel, F. (2010). Bilimsel araştırma yöntemleri. (5. Baskı). Ankara: Pegem Akademi.

Carlson, J., ve Daehler, K. R. (2019). The refined consensus model of pedagogical content knowledge in science education. In A. Hume, R. Cooper ve A. Borowski (Eds.), Repositioning pedagogical content knowledge in teachers' knowledge for teaching science (s. 77-92). Singapore, Springer. 
Carpendale, J. A. (2018). Collaborative CoRe design for year 10 electricity and magnetism: Professional development for enhancing practising science teachers' PCK. Yayımlanmamış Doktora Tezi. Orta Doğu Teknik Üniversitesi, Ankara, Türkiye.

Chan, K. K. H., ve Hume, A. (2019). Towards a consensus model: Literature review of how science teachers' pedagogical content knowledge is investigated in empirical studies. A. Hume, R. Cooper ve A. Borowski (Eds.), Repositioning pedagogical content knowledge in teachers' knowledge for teaching science içinde (s.3-76). Singapore, Springer.

Chan, K. K. H., Rollnick, M., ve Gess-Newsome, J. (2019). A grand rubric for measuring science teachers' pedagogical content knowledge. A. Hume, R. Cooper ve A. Borowski (Ed.), Repositioning pedagogical content knowledge in teachers' knowledge for teaching science içinde (s. 251269). Singapore, Springer.

Fraenkel, J. R., ve Wallen, N. E. (2006). How to design and evaluate research in education. (6. Baskı). New York: McGraw-Hill International Edition.

Mavhunga, E. (2018). Revealing the structural complexity of component interactions of topic-specific PCK when planning to teach. Research in Science Education. https://doi.org/10.1007/s11165-018-9719-6.

Milli Eğitim Bakanlığı [MEB] (2018). Kimya dersi öğretim programı. Ankara: Milli Eğitim Bakanlığı Yayınları.

Park, S., ve Oliver, J. S. (2008). Revisiting the conceptualization of pedagogical content knowledge (PCK): PCK as a conceptual tool to understand teachers as professionals. Research in Science Education, 38(3), 261-284.

Park, S., Jang, J. Y., Chen, Y. C., ve Jung, J. (2011). Is pedagogical content knowledge (PCK) necessary for reformed science teaching?: Evidence from an Empirical Study. Research in Science Education, 41, pp. 245-260.

Park, S., Suh, J., ve Seo, K. (2018). Development and validation of measures of secondary science teachers' PCK for teaching photosynthesis. Research in Science Education, 48, 549-573.

Park, S., ve Suh, J. K. (2019). The PCK Map Approach to Capturing the Complexity of Enacted PCK (ePCK) and Pedagogical Reasoning in Science Teaching. In A. Hume, R. Cooper ve A. Borowski (Ed.), Repositioning pedagogical content knowledge in teachers' knowledge for teaching science (s.185-197). Singapore, Springer.

Schön, D. A. (1987). Educating the reflective PMactitioner: Toward a new design for teaching and learning in the professions. San Francisco: Jossey-Bass. 
Shulman, L. (1986). Those who understand: knowledge growth in teaching. Educational Researcher, 15(1), 4-14.

Shulman, L. S. (1987). Knowledge and teaching: Foundations of the new reform. Harvard Educational Review, 57(1), 1-22.

Simpson, M., ve Tuson, J. (2003). Using observations in small-scale research: A beginner's guide (revised edition). Glasgow, United Kingdom: The SCRE Centre, University of Glasgow.

Van Driel, J. H., Berry, A., ve Meirink, J. A. (2014). Research on science teacher knowledge. N. Lederman ve S. K. Abell (Eds.), Handbook of research on science education içinde (2. ed., s.848-870). London: Taylor \& Francis.

\section{Kaynakça Bilgisi / Citation Information}

Belge-Can, H. (2020). Kimya öğretmenlerinin pedagojik muhakemelerinin öğretim döngüsü boyunca değerlendirilmesi. OPUS-Uluslararası Toplum Araştırmaları Dergisi, 15(22), 994-1014. DOI: 10.26466/opus.653280 